\title{
Posterior Auricular Artery-Middle Cerebral Artery Bypass: A Rare Superficial Temporal Artery Variant with Well-developed Posterior Auricular Artery-Case Report
}

\author{
Joji TOKUGAWA, ${ }^{1}$ Yasuaki NaKAO,,${ }^{1}$ Kentaro KudO, ${ }^{1}$ Koji IIMURA, ${ }^{1}$ \\ Takanori ESAKI, ${ }^{1}$ Takuji YAMAMOTO, ${ }^{1}$ and Kentaro MORI ${ }^{1}$
}

${ }^{1}$ Department of Neurosurgery, Juntendo University Shizuoka Hospital, Izunokuni, Shizuoka

\begin{abstract}
The posterior auricular artery (PAA) is one of the branches of the external carotid artery, but is usually too small for use as a donor artery for middle cerebral artery (MCA) territory revascularization. An extremely unusual case of PAA-MCA anastomosis was performed in a patient requiring MCA territory revascularization because the superficial temporal artery (STA) parietal branch was absent and the PAA was large enough. A 65-year-old man developed mild motor weakness in the right extremities caused by multiple small infarctions. Single photon emission computed tomography (CT) revealed deterioration of the vascular reserve capacity in the left MCA area. Cerebral angiography showed severe stenosis in the C2 portion of the left internal carotid artery, absence of the parietal branch of the left STA, and a well-developed PAA extending to the parietal area. The patient underwent STA (frontal branch)-MCA and PAA-MCA double anastomosis, and has suffered no stroke or transient ischemic attack. The STA with no bifurcation is known as a rare variation. The PAA also occurs with size variations but well-developed PAA is thought to be extremely rare. PAA can be used as a donor artery for MCA territory revascularization if the vessel size is suitable. Preoperative evaluation of the anatomy is mandatory for harvesting the arteries.
\end{abstract}

Key words: carotid artery stenosis, extracranial-intracranial bypass, low-flow bypass, revascularization, stroke

\section{Introduction}

The superficial temporal artery (STA) is the most widely used donor artery for middle cerebral artery (MCA) territory revascularization, but if the STA cannot be used, other extracranial arteries such as the occipital artery $(\mathrm{OA}),{ }^{1)}$ contralateral STA (bonnet bypass), ${ }^{2,3)}$ or arterial graft $^{4,5)}$ are well-known substitutes for the donor vessel. The posterior auricular artery (PAA) is a small branch that arises from the posterior aspect of the external carotid artery, courses upward and backward, passes through the groove between the cartilage of the auricle and the mastoid process ${ }^{6}{ }^{6}$ and supplies a relatively small area of skin posterior to the ear. ${ }^{7)}$ Conventional cerebral angiography generally shows the PAA as slender and thus too small for use as a donor artery. We treated a patient requiring MCA territory revascularization with a PAA-MCA bypass because the STA parietal branch was

Received June 25, 2012; Accepted December 6, 2012 absent and the PAA was unusually large, as if supplying the STA territory.

\section{Case Report}

A 65-year-old man, with a long history of diabetes and hypertension, suffered mild motor weakness in the right extremities. Magnetic resonance imaging revealed multiple small infarctions in the left cerebral hemisphere (Fig. 1). Digital subtraction angiography showed a severe stenosis in the left C2 portion of the internal carotid artery (Fig. 2) and a well-developed PAA extending to the parietal area (Fig. 3A). Single photon emission CT using the double injection method $^{8)}$ showed the regional cerebrovascular reserve capacity was reduced in the left MCA territory (Table 1). Although the patient was receiving adequate volume expansion and antiplatelet therapies, transient ischemic attacks such as sensory disturbance and/or mild motor weakness in the right were frequently observed. As the patient was thought to be in a hemodynamically 


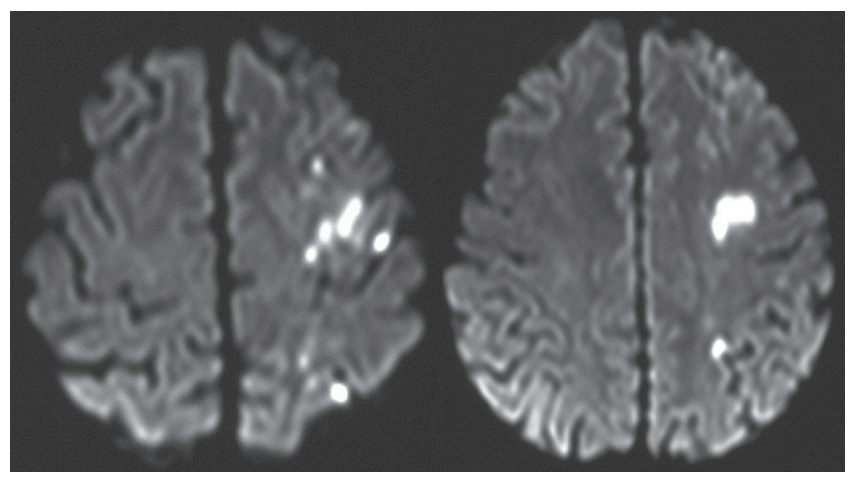

Fig. 1 Diffusion-weighted magnetic resonance (MR) image demonstrating multiple fresh infarctions in both the cortical and subcortical areas of the left cerebral hemisphere, indicating the duplex of hemodynamic compromise and artery-to-artery embolism.

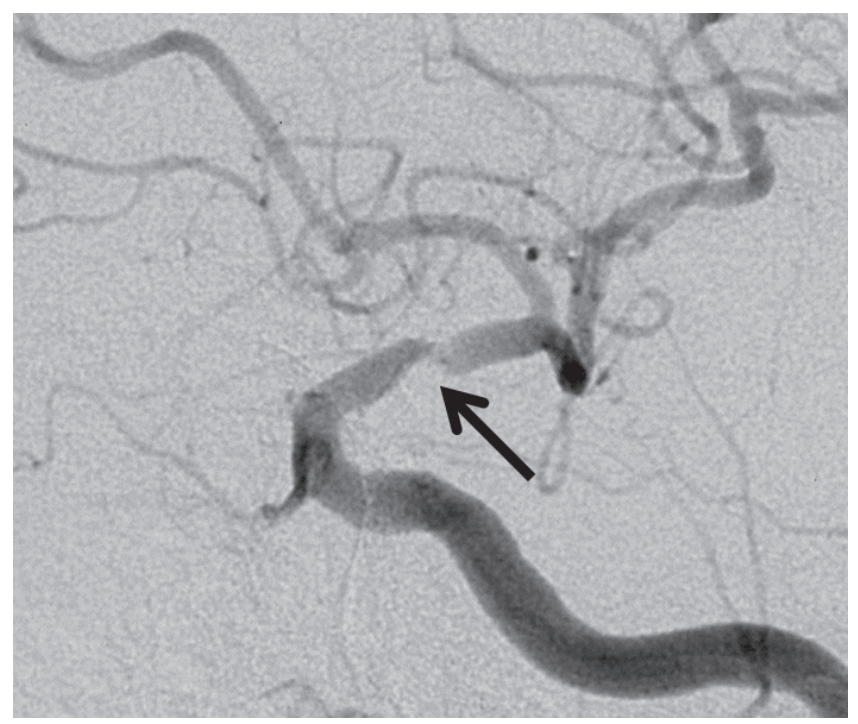

Fig. 2 Digital subtraction angiogram of the left common carotid artery, oblique view, clearly demonstrating severe stenosis (arrow) in the left $\mathrm{C} 2$ portion. compromised state, revascularization for the left MCA territory was performed approximately 2 months after the initial onset.

The patient underwent STA (frontal branch)-MCA and PAA-MCA double anastomosis. The STA frontal branch and PAA were traced with the Doppler probe passed over the skin before the surgery (Fig. 4). The skin incision was started in front of the left ear to expose the proximal portion of the STA. The incision was gently curved posteriorly along the upper edge of the ear until just above the PAA. The PAA was harvested by the cut down method. After an adequate length of the PAA was exposed (approximately as far as the linear temporalis), the incision was gently curved to the frontal skin towards the midline. After reflecting the skin flap, the STA frontal branch was dissected from the bed as far as the proximal portion already exposed earlier. A small craniotomy was made over the sylvian fissure. The recipient branches of the MCA were identified underneath the arachnoid membrane of the sylvian fissure according to the size of the donor and recipient arteries. The STA and PAA were anastomosed with 10-0 nylon to the frontal and temporal branches of the M3 portion, respectively. Blood flow in both the donor and recipient arteries was confirmed with the Doppler probe.

The postoperative course was unremarkable. No skin problems were observed. Postoperative angiography showed good patency of the anastomoses (Fig. 3B). The patient has suffered no stroke or transient ischemic attack.

\section{Discussion}

The PAA has received little attention in the neurosurgical field. Even in standard neuroradiological textbooks, discussion of the PAA is limited. In contrast, the PAA is well-documented in the plastic and reconstructive surgery field because the PAA is frequently used for a pedicled skin flap. ${ }^{9)}$ This artery arises from the posterior aspect

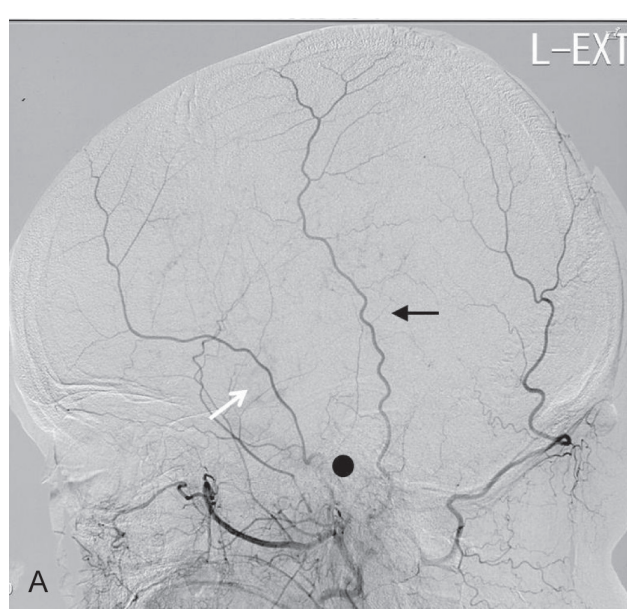

B

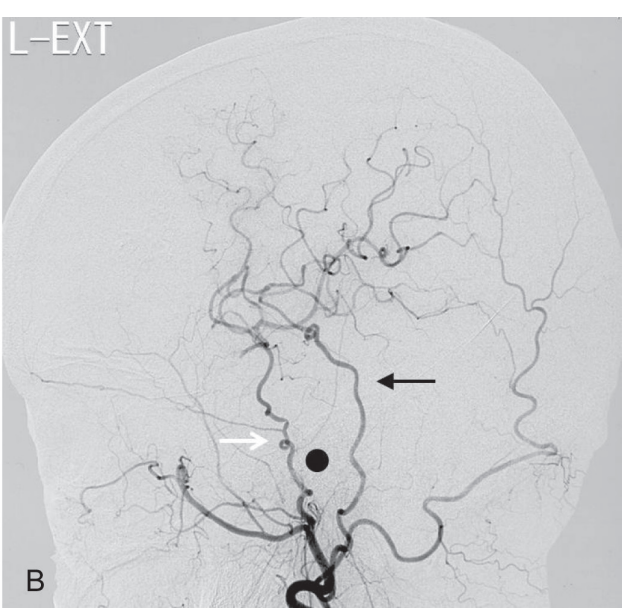

Fig. 3 Pre- (A) and postoperative (B) lateral external carotid arteriograms demonstrating the frontal branch of the superficial temporal artery (STA, white arrows) and posterior auricular artery (black arrows). Note the absence of the parietal branch of the STA in A. Patent anastomoses and sufficient distal flow are demonstrated in B. The black dot indicates the external auditory canal. 
Table 1 Cerebral blood flow findings on single photon emission computed tomography

\begin{tabular}{|c|c|c|c|c|c|c|}
\hline & \multicolumn{2}{|c|}{ Rest (mL/min/100 g) } & \multicolumn{2}{|c|}{ Acetazolamide $(\mathrm{mL} / \mathrm{min} / 100 \mathrm{~g})$} & \multicolumn{2}{|c|}{ Vascular Reserve Capacity (\%) } \\
\hline & Right & Left & Right & Left & Right & Left \\
\hline ACA & 53.79 & 53.83 & 48.30 & 54.17 & -10.21 & 0.63 \\
\hline MCA & 55.76 & 54.26 & 87.00 & 60.00 & 56.03 & 10.58 \\
\hline M2 anterior & 56.21 & 56.21 & 85.78 & 59.16 & 52.61 & 5.25 \\
\hline M2 posterior & 56.00 & 53.79 & 90.01 & 62.55 & 60.73 & 16.29 \\
\hline
\end{tabular}

ACA: anterior cerebral artery, MCA: middle cerebral artery.

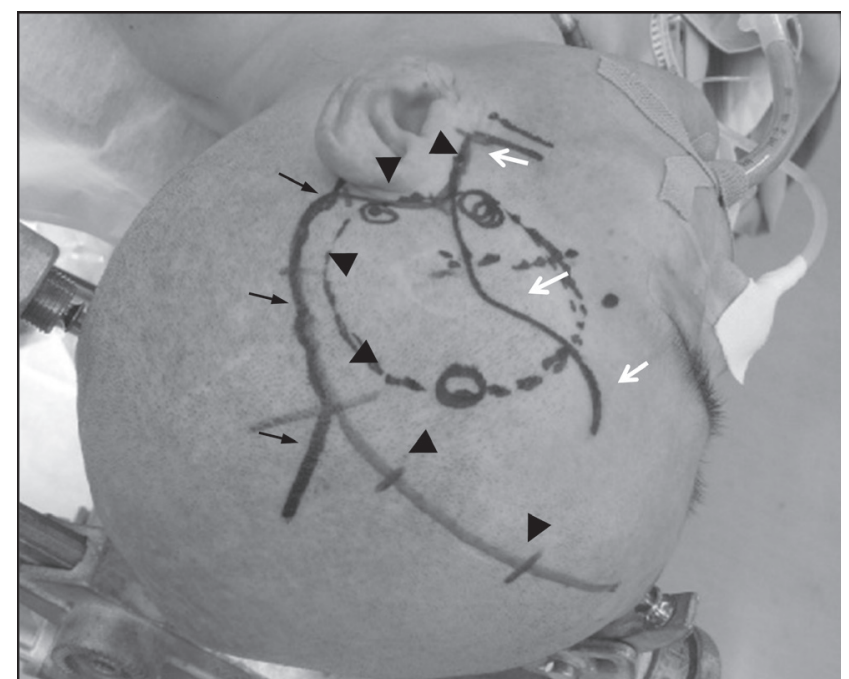

Fig. 4 Photograph showing the tracing of the superficial temporal artery frontal branch (white arrows) and posterior auricular artery (black arrows) on the skin, and the skin incision (arrowheads) marked according to the paths of the arteries.

of the external carotid artery and passes dorsal to the external auditory canal, and has a consistent cutaneous distribution based on a cadaver study. ${ }^{10)}$ However, the PAA supplies not only the skin of the auricle and the postauricular skin, but also the extracranial facial nerve in the stylomastoid foramen area. ${ }^{11,12)}$ The PAA gives rise to the stylomastoid artery toward the facial nerve trunk in $70-80 \%$ of individuals. Therefore, surgeons must exercise great care when harvesting the artery.

Anatomical studies of the STA have revealed variations or racial differences. ${ }^{13-18)}$ A type of STA with no parietal branch was found among 50 autopsy specimens, ${ }^{14)}$ and another case was found in 27 specimens. ${ }^{16)}$ This type looks quite similar to our case. However, these previous studies focused purely on the STA, with no description of the PAA. This type is thought to be rare, based on other anatomical studies which did not report this type of STA. ${ }^{13,15,18)}$ Our present case is also thought to be a rare type with no parietal branch of the STA and a thick PAA supplying the parietal region of the scalp. We could use this well-developed PAA as a donor artery.

PAA-STA anastomosis was reported in two of 65 cases over a 5-year period, but no detailed description was available. ${ }^{19)}$ The other patients were treated by STA-MCA anastomoses. Recently, PAA-STA anastomosis was used in repeat surgery for moyamoya disease. ${ }^{7)}$ In their case, the STA and OA had already been used as the donor arteries in previous surgeries, and the changed hemodynamic status may have affected the blood supply to the PAA. The PAA is usually not a candidate donor artery because of the slender appearance on conventional angiography, but neurosurgeons should be aware of the variation in size as in the present case.

The present case shows that the PAA can be used as a donor artery for MCA territory revascularization if the vessel size is suitable. As the branches of the external carotid artery may have some variations, as in our case, meticulous preoperative study is necessary for planning of the revascularization.

\section{Conflicts of Interest Disclosure}

The authors have no funding and financial interest.

\section{References}

1) Spetzler R, Chater N: Occipital arteryEmmiddle cerebral artery anastomosis for cerebral artery occlusive disease. Surg Neurol 2: 235-238, 1974

2) Sanada Y, Kamiyama H, Iwaisako K, Yoshimine T, Kato A: "Bonnet" bypass to proximal trunk of middle cerebral artery with a radial artery interposition graft: technical note. Minim Invasive Neurosurg 53: 203-206, 2010

3) Spetzler RF, Roski RA, Rhodes RS, Modic MT: The "bonnet bypass". Case report. J Neurosurg 53: 707-709, 1980

4) Büyükmumcu M, Güney O, Ustün ME, Uysal II, Seker M: Proximal superficial temporal artery to proximal middle cerebral artery bypass using a radial artery graft: an anatomic approach. Neurosurg Rev 27: 185-188, 2004

5) Tachibana E, Suzuki Y, Harada T, Saito K, Gupta SK, Yoshida $\mathrm{J}$ : Bypass surgery using a radial artery graft for bilateral extracranial carotid arteries occlusion. Neurosurg Rev 23: $52-55,2000$

6) Newton TH, Potts DG: Radiology of the Skull and Brain, Book 2. St Louis, CV Mosby, 1974, p 1260

7) Horiuchi T, Kusano Y, Asanuma M, Hongo K: Posterior auricular artery-middle cerebral artery bypass for additional surgery of moyamoya disease. Acta Neurochir (Wien) 154: 455-456, 2012 
8) Mori K, Maeda M, Asegawa S, Masuda Y, Takeoka K: A new technique for quantitative imaging of cerebrovascular reserve capacity using a double injection method with N-isopropyl-p-[123I]iodoamphetamine. Neuroimage 3: 89-96, 1996

9) Moschella F, Cordova A, Pirrello R, De Leo A: The supraauricular arterial network: anatomical bases for the use of superior pedicle retro-auricular skin flaps. Surg Radiol Anat 24: 343-347, 2003

10) McKinnon BJ, Wall MP, Karakla DW: The vascular anatomy and angiosome of the posterior auricular artery. A cadaver study. Arch Facial Plast Surg 1: 101-104, 1999

11) Moreau S, Bourdon N, Salame E, Goullet de Rugy M, Babin E, Valdazo A, Delmas P: Facial nerve: vascular-related anatomy at the stylomastoid foramen. Ann Otol Rhinol Laryngol 109: 849-852, 2000

12) Upile T, Jerjes W, Nouraei SA, Singh SU, Kafas P, Sandison A, Sudhoff H, Hopper C: The stylomastoid artery as an anatomical landmark to the facial nerve during parotid surgery: a clinico-anatomic study. World J Surg Oncol 7: 71, 2009

13) Chen TH, Chen CH, Shyu JF, Wu CW, Lui WY, Liu JC: Distribution of the superficial temporal artery in the Chinese adult. Plast Reconstr Surg 104: 1276-1279, 1999

14) Marano SR, Fischer DW, Gaines C, Sonntag VK: Anatomical study of the superficial temporal artery. Neurosurgery 16: 786-790, 1985

15) Mwachaka P, Sinkeet S, Ogeng’o J: Superficial temporal artery among Kenyans: pattern of branching and its relation to pericranial structures. Folia Morphol (Warsz) 69: 51-53, 2010

16) Pinar YA, Govsa F: Anatomy of the superficial temporal artery and its branches: its importance for surgery. Surg Radiol Anat 28: 248-253, 2006

17) Stock AL, Collins HP, Davidson TM: Anatomy of the superficial temporal artery. Head Neck Surg 2: 466-469, 1980

18) Tayfur V, Edizer M, Magden O: Anatomic bases of superficial temporal artery and temporal branch of facial nerve. $J$ Craniofac Surg 21: 1945-1947, 2010

19) Gratzl O, Schmiedek P, Spetzler R, Steinhoff H, Marguth F: Clinical experience with extra-intracranial arterial anastomosis in 65 cases. J Neurosurg 44: 313-324, 1976

Address reprint requests to: Joji Tokugawa, MD, $\mathrm{PhD}$, Department of Neurosurgery, Juntendo University Shizuoka Hospital, 1129 Nagaoka, Izunokuni, Shizuoka 410-2295, Japan. e-mail:dr_george1972@hotmail.com 